\title{
Three-Phase Distillation in Packed Towers: Short-Cut Modelling and Parameter Tuning
}

\author{
Olivier Villain*, Richard Faber, Pu Li, Jens-Uwe Repke and Günter Wozny \\ Technical University of Berlin \\ Institute of Process and Plant Technology and Technical Acoustics \\ Sekr. KWT9, Strasse des 17. Juni 135, 10623, Germany
}

\begin{abstract}
A short-cut model is developed for the predictive simulation of a three-phase distillation process in packed towers. The model is taking into account the mass transfer resistance between the vapour phase and both liquid phases, whereas equilibrium is assumed between the two liquid phases. The development of the model was strongly connected with a systematic experimental investigation study of three-phase operated packings. Thus, it was possible to estimate unknown parameters occurring in the model. Therefore, a powerful parameter estimation technique which is able to handle a large number of experimental data sets was applied. Both the simulation model and the parameter estimation method are discussed in this contribution. The first results are in good agreement with the experimental data of the packed column.
\end{abstract}

Keywords: Heterogeneous azeotropic distillation; packed column; Experimental investigation; Parameter estimation

\section{Introduction}

In our own previous study, a nonequilibrium model for three-phase distillation in a packed column was developed and validated with experimental investigations (Repke et al., 2003). Thus the accuracy of the model was proved and the understanding of the mechanism governing the three-phase distillation with packing was significantly improved. But the theoretical knowledge about three-phase distillation with packing remains limited. As a fact, predictive calculation of the separation efficiency is still not supported by the simulation, and existing models are generally not convenient for common industrial strategic tasks. As a result, new techniques for the improvement of the design and the industrial application of packed towers for the three-phase distillation are needed. Therefore, the development of a predictive short-cut modelling method considering the occurrence of a second liquid phase on the packing is required.

\section{Model introduction}

A model is developed for the prediction of the separation efficiency of a three-phase distillation process in packed towers. The model is based on the calculation of the

${ }^{*}$ Corresponding Author: olivier.villain@tu-berlin.de 
Height of a Transfer Unit (HTU) of a three-phase operated packing for the multicomponent case. The method proposed in (Taylor and Krishna, 1993) is considered for the calculation of the multicomponent mass transfer coefficients, whereas new methods are proposed to scale those coefficients for one component and to take into account the occurrence of a second liquid phase on the packing. The starting point for the multicomponent mass transfer coefficient calculation is the binary mass transfer calculation, for example as proposed in (Billet, 1995) and shown in equation (1).

$\beta^{\mathrm{V}} \mathrm{a}_{\mathrm{Ph}}=\mathrm{C}^{\mathrm{V}} \frac{\mathrm{a}^{2}}{2 \sqrt{\varepsilon}} \frac{1}{\sqrt{\varepsilon-\mathrm{h}_{\mathrm{L}}}} \mathrm{D}^{\mathrm{v}}\left(\frac{\mathrm{u}^{\mathrm{v}} \rho^{\mathrm{v}}}{\mathrm{a} \eta^{\mathrm{V}}}\right)^{\mathrm{m}}\left(\frac{\eta^{\mathrm{V}}}{\mathrm{D}^{\mathrm{V}} \rho^{\mathrm{v}}}\right)^{\mathrm{n}} \frac{\mathrm{a}_{\mathrm{Ph}}}{\mathrm{a}}$

In equation (1), the exponential parameters $\mathrm{m}$ and $\mathrm{n}$ given in the literature were determined for binary mixtures in the two-phase case. Therefore, estimated values of those parameters are needed for the new short-cut method. The model presented bases on the HTU/NTU concept for binary mixtures and for the two phase distillation. In the following part of the contribution, the extension of this concept for multi-component mixtures and for the three-phase distillation will be discussed.

\subsection{HTU/NTU Concept for binary systems}

The basic form of the HTU/NTU-concept is relating the packing high with the separation efficiency:

$$
\mathrm{H}=\mathrm{HTU}^{\mathrm{OV}} \times \mathrm{NTU}^{\mathrm{OV}}=\frac{\dot{\mathrm{V}}}{\mathrm{c}_{\mathrm{t}}^{\mathrm{V}} \mathrm{A} \beta^{\mathrm{OV}} \mathrm{a}_{\mathrm{Ph}}} \times \int_{\mathrm{y}_{\mathrm{i}, \text { ein }}}^{\mathrm{y}_{\mathrm{i}, \text { aus }}} \frac{\mathrm{dy}}{\mathrm{y}_{\mathrm{i}}^{*}-\mathrm{y}_{\mathrm{i}}}
$$

where the binary overall gas mass transfer coefficients are calculated as follow:

$$
\frac{1}{\beta^{\mathrm{OV}}}=\frac{1}{\beta^{\mathrm{V}}}+\frac{\mathrm{c}_{\mathrm{t}}^{\mathrm{V}}}{\mathrm{c}_{\mathrm{t}}^{\mathrm{L}}} \frac{\mathrm{m}}{\beta^{\mathrm{L}}}
$$

\subsection{Definition of a multi-component mass transfer coefficient}

As an analogy to the binary two-phase distillation case, the following multi-component formulation for the HTU/NTU concept is considered for the next steps of the calculation:

$$
\mathrm{H}=\mathrm{HTU}_{\mathrm{i}}^{\mathrm{OV}} \times \mathrm{NTU}_{\mathrm{i}}^{\mathrm{OV}}=\frac{\dot{\mathrm{V}}}{\mathrm{c}_{\mathrm{t}}^{\mathrm{V}} \mathrm{A} \bar{\beta}_{\mathrm{i}}^{\mathrm{OV}} \mathrm{a}_{\mathrm{Ph}}} \times \int_{\mathrm{y}_{\mathrm{i}, \text { ein }}}^{\mathrm{y}_{\mathrm{i} \text {,aus }}} \frac{\mathrm{dy}}{\mathrm{y}_{\mathrm{i}}^{*}-\mathrm{y}_{\mathrm{i}}}
$$

The detailed calculation method of multi-component mass transfer coefficients is given in (Taylor and Krishna, 1993), as well as the appending overall gas formulation:

$$
\left[\mathrm{k}^{\mathrm{OV}}\right]^{-1}=\left[\mathrm{k}^{\mathrm{V}}\right]^{-1}+\frac{\mathrm{c}_{\mathrm{t}}^{\mathrm{V}}}{\mathrm{c}_{\mathrm{t}}^{\mathrm{L}}}[\mathrm{M}]\left[\mathrm{k}^{\mathrm{L}}\right]^{-1}
$$


Definition of the multi-component mass transfer coefficient

The diffusion flux of the component i can be rearranged to obtain an unique mass transfer coefficient, $\bar{\beta}_{\mathrm{i}}^{\mathrm{OV}}$, called here “overall gas multi-component mass transfer coefficient". The formulation of this coefficient is given in equation (6).

$\bar{\beta}_{\mathrm{i}}^{\mathrm{OV}}=\mathrm{k}_{\mathrm{ii}}^{\mathrm{OV}}-\frac{\mathrm{k}_{\mathrm{ij}}^{\mathrm{OV}} \mathrm{k}_{\mathrm{ik}}^{\mathrm{OV}}}{\mathrm{k}_{\mathrm{ij}}^{\mathrm{OV}}+\mathrm{k}_{\mathrm{ik}}^{\mathrm{OV}}}$

\subsection{Three-phase model}

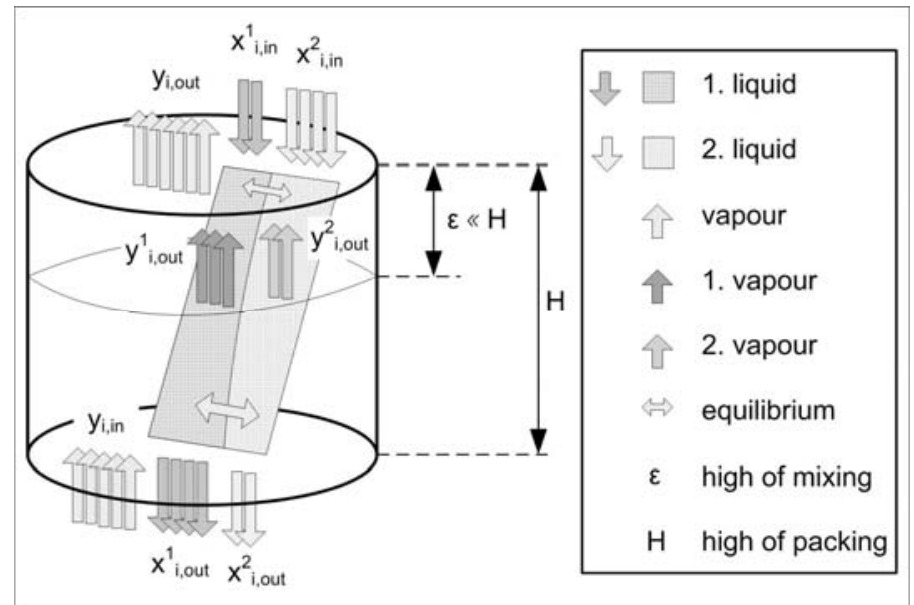

Figure 1. Three-phase model perception

The main idea of the method is presented in Fig. 1: In the heterogeneous case, two vapour streams are considered, resulting from the decomposition of the liquid on the packing surface. Thus, equation (4) can be formulated for both liquid streams in order to obtain the outlet concentrations of both defined vapour streams.

$\mathrm{H}=\mathrm{HTU}_{\mathrm{i}, 1}^{\mathrm{OV}} \times \mathrm{NTU}_{\mathrm{i}, 1}^{\mathrm{OV}}=\mathrm{HTU}_{\mathrm{i}, 2}^{\mathrm{OV}} \times \mathrm{NTU}_{\mathrm{i}, 2}^{\mathrm{OV}}$

where $\quad \mathrm{HTU}_{\mathrm{i}, 1}^{\mathrm{OV}}=\frac{\dot{\mathrm{V}}}{\mathrm{c}_{\mathrm{i}}^{\mathrm{V}} \mathrm{A} \bar{\beta}_{\mathrm{i}, 1}^{\mathrm{OV}} \mathrm{a}_{\mathrm{Ph}} \mathrm{f}_{\mathrm{r}}} \quad$ and $\mathrm{HTU}_{\mathrm{i}, 2}^{\mathrm{OV}}=\frac{\dot{\mathrm{V}}}{\mathrm{c}_{\mathrm{i}}^{\mathrm{V}} \mathrm{A} \bar{\beta}_{\mathrm{i}, 2}^{\mathrm{OV}} \mathrm{a}_{\mathrm{Ph}}\left(1-\mathrm{f}_{\mathrm{r}}\right)}$

with fr, the superficial distribution of both liquid phases on the packing.

Calculation of the vapour concentration at the packing outlet

The vapour concentration $\mathrm{y}_{\mathrm{i} \text {,aus }}$ obtained at the packing outlet results from the mixing of two vapour flows connected with the two liquid phases (see Fig. 1). $y_{i, \text { aus }}$ can be calculated as follows:

$\mathrm{y}_{\mathrm{i}, \mathrm{aus}}=\frac{\dot{\mathrm{M}}_{1} \mathrm{y}_{\mathrm{i}, \mathrm{aus}}^{1}+\dot{\mathrm{M}}_{2} \mathrm{y}_{\mathrm{i}, \mathrm{aus}}^{2}}{\dot{\mathrm{M}}}$ 


\section{Parameter fitting}

To adjust the process model for the multi-component three-phase case, the exponential parameters of equation (1) have been adjusted based on measurement data taken from the pilot plant with model based parameter estimation techniques.

Generally, if measurement errors are considered for all variables, the size of the parameter estimation problem increases linearly with the number of data sets. As the parameters have been evaluated for different mixtures simultaneously a large number of data sets has been used in parameter estimation. Due to the large number of data sets used, parameter estimation becomes a difficult task. As measurement errors have to be considered for dependent as well as independent variables the parameter estimation problem consists of two tasks: the parameter estimation problem itself and a data reconciliation step to rectify errors in the independent variables measurements. As the individual data sets are coupled over the parameters both steps can not be solved separately. Therefore the parameter estimation problem leads to a large scale optimization problem where the size of the problem increases linearly with the number of data sets. In this study, about 500 data sets are available for estimating the exponential parameters considering measurement errors for 5 independent variables for each data set. A new three stage decomposition strategy has been used for parameter estimation (Faber et al., 2003). The developed parameter estimation approach is able to handle large-scale systems with multiple sets of measurement data. Due to the reduction of the size of the optimization problem it is possible to use standard optimization software.

\section{Results}

A systematic experimental investigation study of three-phase operated packing was realised to support the model development. Additional experimental results from past study at our department are also available for the parameter estimation. A detailed description of the experimental study is given in (Villain et al., 2003).

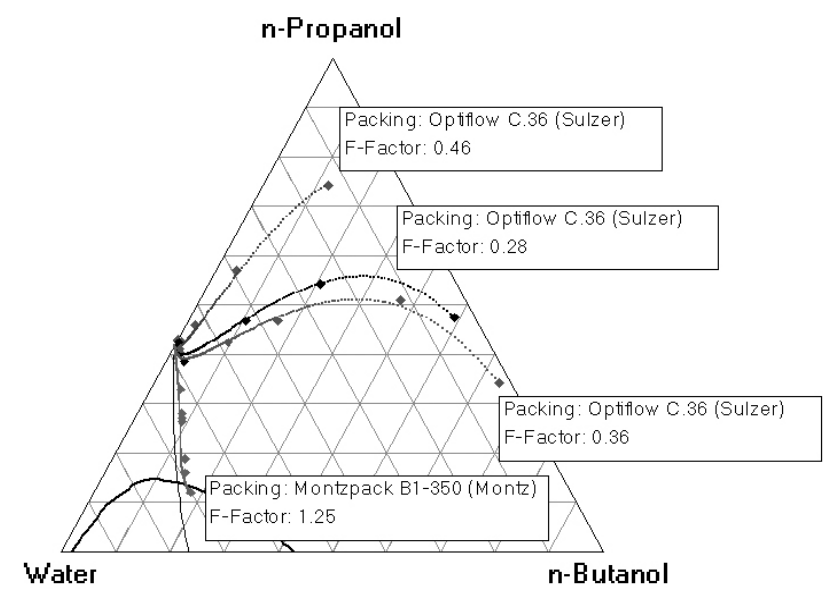

Figure 2. Composition triangle of the distillation in packed column at total reflux for 1propanol/1-butanol/water: experiment and simulation. 
Before the introduced method is applied for the complex heterogeneous case, it is useful to verify the method on the ternary homogeneous distillation. In Fig. 2 and Fig. 3 a comparison between experiment and simulation is shown at the example of the mixture 1-propanol/1-butanol/water. The exponents $\mathrm{m}=0.718$ and $\mathrm{n}=-1.038$ were used for the simulation. These values result from a parameter estimation run with 15 data sets. The deviation from the values given in (Billet, 1995) and the validation of the results will be discussed in the lecture.

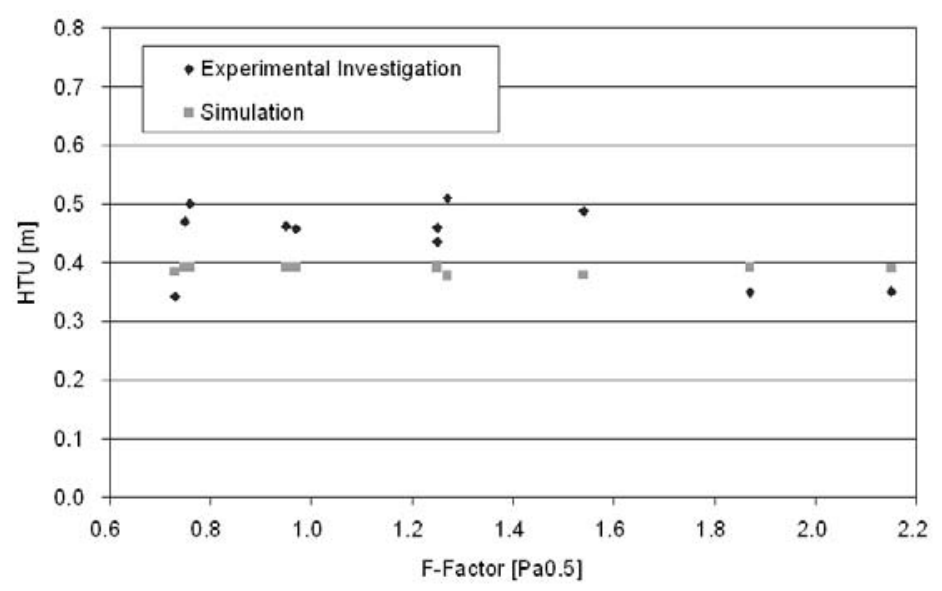

Figure 3. Separation efficiency of the distillation of 1-propanol/1-butanol/water at total reflux with the packing Montzpack B1-350: experiment vs. simulation

Using the estimated parameters, the model describes the experimental concentration profile and the measured separation efficiency with a sufficient accuracy to realise design and planning tasks.

\section{Conclusions}

In this contribution, a short-cut method for the predictive calculation of the separation efficiency of the three-phase distillation in packed column is presented. A powerful parameter estimation procedure is used to realise an accurate model tuning with regard of the experimental results of a systematic investigation study. In a first step, it was possible to determine parameters fitting a range of experiment with a unique mixture and different kinds of packing. The first results are in good agreement with the experimental data of the packed column. The extension of the use of those parameters for any combination of mixtures and packing will be discussed in the presentation and illustrated with examples.

\section{Symbols}

$\begin{array}{lll}\mathrm{a} & \text { total surface area per unit packed volume } & {\left[\mathrm{m}^{2} / \mathrm{m}^{3}\right]} \\ \mathrm{a}_{\mathrm{Ph}} & \text { effective interfacial area per unit packed volume } & {\left[\mathrm{m}^{2} / \mathrm{m}^{3}\right]} \\ \mathrm{A} & \text { free cross-sectional area of the column } & {\left[\mathrm{m}^{2}\right]} \\ \mathrm{C} & \text { packing constant to allow for mass transfer } & {[-]} \\ \mathrm{c}_{\mathrm{t}} & \text { total molar concentration } & {\left[\mathrm{kmol} / \mathrm{m}^{3}\right]}\end{array}$




$\begin{array}{ll}\text { D } & \text { diffusion coefficient } \\ \mathrm{f}_{\mathrm{r}} & \text { superficial distribution of both liquid phases } \\ \mathrm{h}_{\mathrm{L}} & \text { liquid hold-up } \\ \mathrm{k} & \text { multi-component mass transfer coefficient } \\ \mathrm{HTU} & \text { height of a transfer unit } \\ \mathrm{M}, \mathrm{m} & \text { slope of the equilibrium curve } \\ \mathrm{m}, \mathrm{n} & \text { experimental determined parameters } \\ \mathrm{NTU} & \text { number of transfer units } \\ \mathrm{u}^{\mathrm{v}} & \text { superficial vapour velocity } \\ \dot{\mathrm{V}} & \text { molar vapour stream } \\ \beta & \text { binary mass transfer coefficient } \\ \varepsilon & \text { void fraction of packing } \\ \rho & \text { mass density } \\ \eta & \text { dynamic viscosity }\end{array}$

$\left[\mathrm{m}^{2} / \mathrm{s}\right]$
$[-]$
$\left[\mathrm{m}^{3} / \mathrm{m}^{3}\right]$
$[\mathrm{m} / \mathrm{s}]$
$[\mathrm{m}]$
$[-]$
$[-]$
$[-]$
$[\mathrm{m} / \mathrm{s}]$
$[\mathrm{kmol} / \mathrm{s}]$
$[\mathrm{m} / \mathrm{s}]$
$[-]$
$\left[\mathrm{kg} / \mathrm{m}^{3}\right]$
$\left[\mathrm{kg} \cdot \mathrm{m}^{-1} \cdot \mathrm{s}^{-1}\right]$

\section{Subscripts and Superscripts}

1,2 index for first and second liquid phase

in, out inlet, outlet

i component i

L liquid phase

OV overall gas calculation

$\mathrm{V} \quad$ vapour phase

equilibrium

\section{References}

Repke, J.-U., Villain, O., Wozny, G., 2003, A Nonequilibrium model for three-phase Distillation in a packed column: modelling and experiments, ESCAPE-13, Lappeenranta, Finland.

Taylor, R.; Krishna, R., 1993, Multicomponent Mass Transfer, John Wiley \& Sons, inc., New York.

Billet, R., 1995, Packed Towers. VCH Verlagsgesellschaft GmbH, Weinheim.

Faber, R., Li, P., Wozny, G, 2003, Sequential parameter estimation for large-scale systems with multiple data sets. Part I: Computational Framework. Ind. Eng. Chem. Res., 42(23), 5850 5860.

Villain, O.; Repke, J.-U.; Wozny, G.: Performance characterization of three-phase operated packing. AIChE annual 2003, San Francisco, 16-21 November

\section{Acknowledgements}

Financial support to this work from the Deutsche Forschungsgemeinschaft (DFG) under the project contract LI806/4-3 and the German Federation of Industrial Cooperative Research Associations "Otto von Guericke" (AIF) under the project contract $13251 \mathrm{~N}$ is gratefully acknowledged. 